\title{
One-Step Electrochemical Deposition of Reduced Graphene Oxide-Bismuth Nanocomposites for Determination of Lead
}

\author{
Xueping Hu, ${ }^{\text {a,b }}$ Dawei Pan, ${ }^{\text {a,z }}$ Mingyue Lin, ${ }^{\text {a,b }}$ Haitao Han, ${ }^{a}$ and Fei Li ${ }^{c}$ \\ ${ }^{a}$ Key Laboratory of Coastal Environmental Processes and Ecological Remediation, Yantai Institute of Coastal Zone \\ Research (YIC), Chinese Academy of Sciences (CAS); Shandong Provincial Key Laboratory of Coastal Environmental \\ Processes, YICCAS, Yantai, Shandong 264003, People's Republic of China \\ ${ }^{b}$ University of Chinese Academy of Sciences, Beijing 100049, People's Republic of China \\ ${ }^{c}$ The Key Lab in Molecular and Nano-materials Probes of the Ministry of Education of China, \\ College of Chemistry, Chemical Engineering and Materials Science, Shandong Normal University, Jinan, \\ Shandong 250014, People's Republic of China
}

\begin{abstract}
The novel reduced graphene oxide-bismuth (RGO-Bi) nanocomposites were successfully synthesized through one-step electrochemical reduced deposition and used to modify disposable screen-printed electrode (SPE) for determination of $\mathrm{Pb}$ (II). By electrochemical deposition, a large number of Bi particles were distributed on RGO. Combined the unique structure and electronic properties of RGO with the ability of $\mathrm{Bi}$ to form alloys with other metals, the RGO-Bi/SPE has shown wide linear range and low detection limit for determination of $\mathrm{Pb}$ (II). Additionally, the RGO-Bi/SPE was successfully applied to the rapid determination of $\mathrm{Pb}(\mathrm{II})$ in real coastal sediment pore waters.

(C) 2015 The Electrochemical Society. [DOI: 10.1149/2.0021509eel] All rights reserved.
\end{abstract}

Manuscript submitted May 14, 2015; revised manuscript received June 17, 2015. Published June 30, 2015

Heavy metal pollution is becoming more and more serious in the coastal zone environment. ${ }^{1}$ Electrochemical techniques are widely used in the determination of metal ions owing to the advantages of low cost, high sensitivity, and great convenience in operation, etc. ${ }^{2}$ Recently, various bismuth-based electrodes have been extensively used for heavy metals detection through anodic stripping voltammetry (ASV) instead of mercury-based electrodes ${ }^{3-5}$ owing to the low toxicity, wide potential window, and insensitivity to dissolved oxygen, ect. ${ }^{6,7}$ Reduced graphene oxide (RGO) is a new carbon nanomaterial, which has been widely used for its unique structure and electronic properties. ${ }^{8-11}$ Many bismuth-based electrodes modified with nanomaterials, ${ }^{8,12-17}$ such as carbon nanotube, graphene, etc., have been reported for the determination of heavy metals.

In this paper, we report a new method to fabricate a RGO-Bi nanocomposite modified SPE (RGO-Bi/SPE) by one-step electrochemical deposition. $\mathrm{Pb}$ (II) was used as a model to be detected at RGO-Bi/SPE because $\mathrm{Pb}$ (II) is one of the major pollutants in both terrestrial and aquatic ecosystems. ${ }^{18,19}$ The linear response was in the concentration range of $0.05-20 \mu \mathrm{M}$ with a detection limit of $6.8 \mathrm{nM}$ in the optimized situation. The repeatability of the RGO-Bi/SPE was also excellent with the RSD of $4.6 \%$.

\section{Experimental}

Materials and instruments. - All chemicals and reagents were of analytical grade. The morphologies of modified electrodes were characterized by scanning electron microscopy (SEM Hitachi S-4800). Inductively coupled plasma-mass spectrometry (ICP-MS, ELAN DRC) was used for comparative testing. Electrochemical Work Station (CHI 660D) was used throughout all electrochemical experiments. SPE which includes a screen-printed carbon working electrode $(3 \mathrm{~mm}$ in diameter), carbon auxiliary electrode and a silver chloride reference electrode were purchased from Taiwan Chanpu Science and Technology Company.

Preparation of the RGO-Bi/SPE electrode.- Prior to use, SPE was rinsed and ultrasonicated with deionized water and then subjected to potential cycling $(-0.6 \sim 0.6 \mathrm{~V}, 10 \mathrm{mV} / \mathrm{s})$ in $0.5 \mathrm{M} \mathrm{H}_{2} \mathrm{SO}_{4}$. $\mathrm{Bi}(\mathrm{III})$ solution $(120 \mathrm{mg} / \mathrm{L})$ was mixed with the prepared $\mathrm{GO}(1.0 \mathrm{mg} / \mathrm{mL})$ dispersion in volume ratio of $1: 2$ and ultrasonicated for $1 \mathrm{~min}$. Subsequently, $5 \mu \mathrm{L}$ mixed GO-Bi(III) suspensions were dropped on the surface of SPE and dried using an infrared lamp. Then the modified SPE was dipped into $10 \mathrm{~mL} \mathrm{0.1} \mathrm{M} \mathrm{HAc-NaAc}(\mathrm{pH} \mathrm{4.5)}$ and electrochemically reduced at $-1.3 \mathrm{~V}$ for $500 \mathrm{~s}$. As a contrast, RGO/SPE

${ }^{\text {zE} E-m a i l: ~ d w p a n @ y i c . a c . c n ~}$ and $\mathrm{Bi} / \mathrm{SPE}$ were prepared through dropping $5 \mu \mathrm{L} \mathrm{GO}$ and $\mathrm{Bi}(\mathrm{III})$ solutions on the SPE and applying a constant potential of $-1.3 \mathrm{~V}$ for 500 s respectively.

Electrochemical analysis procedure.- $\mathrm{Pb}$ (II) was preconcentrated by applying a constant potential of $-1.2 \mathrm{~V}$ for $300 \mathrm{~s}$ and then the oxidation responses of $\mathrm{Pb}$ were investigated by differential pulse voltammetry (DPV).

Preparation of Sediment Sample.- Sediment samples were collected from the intertidal zone of bohai, Shandong, China. Sample treatments were according to the previous report. ${ }^{20}$

\section{Results and Discussion}

Characterization of the RGO-Bi/SPE electrodes.- As shown in the Figures $1 \mathrm{~A}$ and $1 \mathrm{~B}, \mathrm{CV}$ s at GO/SPE and bare SPE were almost the same. The RGO/SPE showed an excellent electrochemical performance for the good conductivity of RGO. The CV of RGO-Bi/SPE always presented a good electrochemical performance with an obvious oxidation peak of bismuth. In Figures 1C and 1D, the RGO on the surface of SPE was almost smooth and with some little drapes, however, the surface morphology of RGO-Bi/SPE was much rougher and a large number of particles in 30 50 nm diameter were distributed on it. The electrochemical deposition of GO and Bi(III) were occurred simultaneously in buffer solution. Owning to the percentage of GO is higher than $\mathrm{Bi}(\mathrm{III})$ and the reduction peak of GO is more negative, so the reduction of $\mathrm{Bi}(\mathrm{III})$ would form a nucleus and coalesce with the surrounding $\mathrm{Bi}(\mathrm{III})$ and finally result in the nanoparticles. The $\mathrm{CV}$ and SEM results indicated that we can put the GO and Bi(III) reduced on the SPE simultaneously through an one-step electrochemical reduced deposition method.

Properities of the sensors. - From the Figure 2, two small oxidation peaks of $\mathrm{Pb}$ can be seen at RGO/SPE and Bi/SPE. While the peak current of $\mathrm{Pb}$ at $\mathrm{RGO}-\mathrm{Bi} / \mathrm{SPE}$ was more than the total peak current at the RGO/SPE and Bi/SPE. These results suggested that the RGO-Bi/ $\mathrm{SPE}$ has a favorable response to the $\mathrm{Pb}$ (II). As shown in Figure 2, the oxidation peak potentials of $\mathrm{Pb}$ at $\mathrm{Bi} / \mathrm{SPE}$ and $\mathrm{RGO}-\mathrm{Bi} / \mathrm{SPE}$ shifted negatively. It may be caused by that the bismuth and $\mathrm{Pb}$ formed alloys, which can make the oxidation of $\mathrm{Pb}$ easier and the oxidation peak potential more negative.

Optimization of the experiment conditions. - To optimize the electrochemical responses of $\mathrm{Pb}(\mathrm{II})$ at $\mathrm{RGO}-\mathrm{Bi} / \mathrm{SPE}$, the ratio and volume of GO-Bi(III) mixed solution, deposition potential and deposition time 

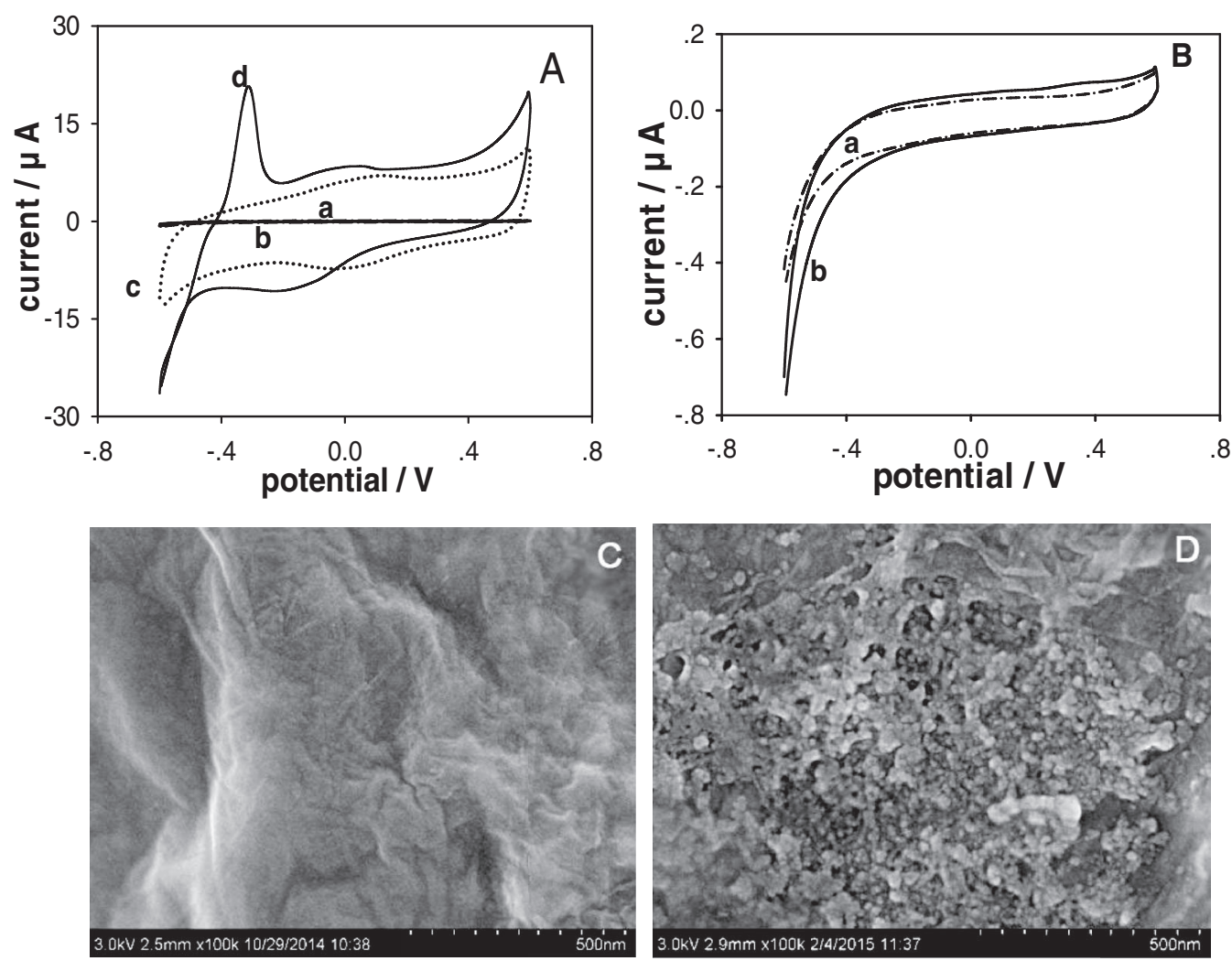

Figure 1. Cyclic voltammograms (A and B) of bare SPE (a) GO/SPE (b) RGO/SPE (c) and RGO-Bi/SPE (d) in 0.1 M HAc-NaAc (pH 4.5) solution in the potential range of -0.6 to $0.6 \mathrm{~V}$. Scan rate: $50 \mathrm{mV} / \mathrm{s}$. SEM pictures of RGO/SPE (C) and RGO-Bi/SPE (D).

were studied in $0.1 \mathrm{M} \mathrm{HAc-NaAc}(\mathrm{pH} 4.5)$ containing $1 \mu \mathrm{M} \mathrm{Pb}(\mathrm{II})$. The maximum response was obtained when $5 \mu \mathrm{L}$ mixed solution, in which volume ratio of $\mathrm{Bi}(\mathrm{III})$ and $\mathrm{GO}$ solutions was 1:2, was selected with the deposition potential of $-1.2 \mathrm{~V}$ and deposition time of $300 \mathrm{~s}$.

Electrochemical response characteristics. - The calibration curve of the $\mathrm{Pb}(\mathrm{II})$ determination was derived from the DPVs obtained at the RGO-Bi/SPE in 0.1 M HAc-NaAc (pH 4.5) under the optimum conditions. As shown in Figure 3, the resulting calibration plot had a favorable linear range in $0.05 \sim 20 \mu \mathrm{M}$. The equation for linear regression was $i p=1.57 C+0.030$, the linear correlation coefficient and the slope of the calibration plot were 0.998 and $1.57 \pm 0.20$ respectively, with the standard error estimate of 0.24 . The detection

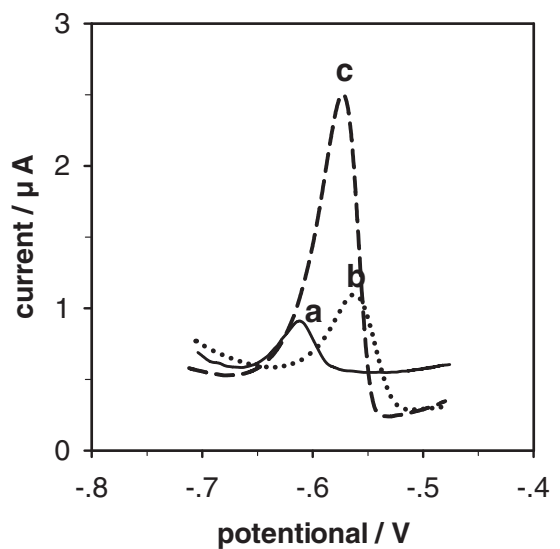

Figure 2. Differential pulse voltammograms of Bi/SPE (a), RGO/SPE (b) and RGO-Bi/SPE (c) in 0.1 M HAc-NaAc (pH 4.5) solution containing $1 \mu \mathrm{M}$ $\mathrm{Pb}(\mathrm{II})$. limit of $\mathrm{Pb}(\mathrm{II})$ at $\mathrm{RGO}-\mathrm{Bi} / \mathrm{SPE}$ was $6.8 \mathrm{nM}(\mathrm{s} / \mathrm{n}=3)$. Compared to the LOD of the similar work that carbon nanomaterials modified electrode, ${ }^{12,16,21}$ the LOD of our work is not improved obviously, but the linear range is wider and the preparation of the modified electrode is easier and more convenient.

Study of interference, reproducibility and stability.- Under the $\pm 5.0 \%$ tolerated ratios, it was found that 100 -fold $\mathrm{K}^{+}, \mathrm{Na}^{+}, \mathrm{Ca}^{2+}$, $\mathrm{Mg}^{2+}, \mathrm{Mn}^{2+}, \mathrm{Cr}^{3+}, \mathrm{Cl}^{-}, \mathrm{NO}_{3}^{-}, 50$-fold $\mathrm{Fe}^{3+}, \mathrm{Zn}^{2+}, 20$-fold $\mathrm{Cu}^{2+}$ and 15 -fold $\mathrm{Sn}^{2+}, \mathrm{Cd}^{2+}$ had no significant effect on the signals of $\mathrm{Pb}$ (II). Reproducibility was investigated for 8 times determination of $1 \mu \mathrm{M} \mathrm{Pb}$ (II) and the relative standard deviation (RSD) was $4.6 \%$. The electrode was continuously used twice each day. After three days,

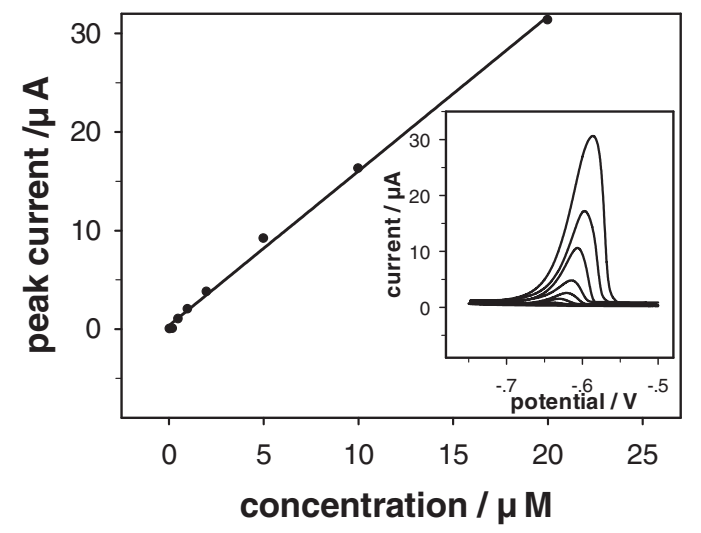

Figure 3. The calibration curve for $\mathrm{Pb}$ (II) determination. Insert: Differential pulse voltammograms obtained using the RGO-Bi/SPE for $\mathrm{Pb}$ (II) at different concentrations (bottom to top: $0.05,0.2,0.8,2,5,10,20 \mu \mathrm{M}$ ) in $0.1 \mathrm{M} \mathrm{HAc}-$ $\mathrm{NaAc}(\mathrm{pH} 4.5)$. 
the current response decreased about $16.5 \%$ compared to its initial response. The stability of the RGO-Bi/SPE is not good. However, considering that the SPE is a disposable electrode, the requirement of stability is not very strict.

Analysis of $\mathrm{Pb}(\mathrm{II})$ in real sample.- The RGO-Bi/SPE was used for the determination of $\mathrm{Pb}$ (II) in real coastal sediment pore water samples. Standard additions of $\mathrm{Pb}$ (II) were applied during the measurement. The calculated result $(70.06 \mathrm{nM})$ was in agreement with the value detected by ICP-MS (68.69 $\mathrm{nM})$.

\section{Conclusions}

In summary, one-step synthetic RGO-Bi/SPE by electrochemical deposition was successfully used to the determination of $\mathrm{Pb}$ (II). It exhibites a favorable electrochemical performance with excellent linear responses in a wide concentration range, together with the limit of $6.82 \mathrm{nM}$ for $\mathrm{Pb}(\mathrm{II})$. Based on the easy establishment of the modified electrode, this electrochemical sensor may have a promising usage in the rapid and on-spot determination of heavy metals in the environments.

\section{Acknowledgments}

This work was financially supported by the National Natural Science Foundation of China (41276093), the Youth Innovation Promotion Association (2011170) and Outstanding Young Scientists of CAS.

\section{References}

1. E. A. Korzun and H. Heck, J Air Waste Manage Assoc, 40, 1220 (1990).

2. G. Herzog and V. Beni, Anal. Chim. Acta, 769, 10 (2013).

3. J. Barek, A. G. Fogg, A. Muck, and J. Zima, Crit. Rev. Anal. Chem., 31, 291 (2001).

4. J. Wang, Electroanalysis, 17, 1341 (2005).

5. A. Economou, Trends Anal. Chem., 24, 334 (2005).

6. J. Saturno, D. Valera, H. Carrero, and L. Fernández, Sens. Actuators. B: Chem., 159, $92(2011)$

7. J. Wang, J. Lu, U. A. Kirgoz, S. B. Hocevar, and B. Ogorevc, Anal. Chim. Acta., 434 29 (2001)

8. Z. Wang, H. Wang, Z. Zhang, and G. Liu, Sens. Actuators. B: Chem., 199, 7 (2014).

9. K. Q. Deng, J. H. Zhou, and X. F. Li, Colloids Surf. B: Biointerfaces, 101, 183 (2013).

10. H. L. Guo, X. F. Wang, Q. Y. Qian, F. B. Wang, and X. H. Xia, ACS Nano., 3, 2653 (2009).

11. J. F. Ping, Y. X. Wang, Y. B. Ying, and J. Wu, Anal. Chem., 84, 3473 (2012).

12. J. F. Ping, Y. X. Wang, J. Wu, and Y. B. Ying, Food. Chem., 151, 65 (2014).

13. D. Yang, L. Wang, Z. L. Chen, M. Megharaj, and R. Naidu, Electrochim. Acta, 132, 223 (2014).

14. D. Agustini, A. S. Mangrich, F. M. Bergamini, and L. H. Marcolino, Talanta, 142 221 (2015).

15. P. F. Niu, F. S. César, G. Martí, C. Ayorac, and A. Roiga, Electrochim. Acta, 165, 155 (2015).

16. G. H. Huang, W. K. Han, J. S. Parkb, and S. G. Kanga, Talanta, 76, 301 (2008)

17. Z. Li, L. Chen, F. He, L. Bu, X. Qin, Q. Xie, and S. Yao, Talanta, 122, 285 (2014)

18. S. Siddiqui, J Saudi Soc. Agric. Sci., 11, 107 (2012).

19. M. F. Chen, M. Y. Chao, and X. Y. Ma, J Appl Electrochem., 44, 337 (2014).

20. S. Cerovac, V. Guzsvány, Z. Kónya, A. M. Ashrafi, I. Švancara, S. Rončević, and B. Dalmacija, Talanta, 134, 640 (2015).

21. H. Xu, L. P. Zeng, S. J. Xing, Y. Z. Xian, and G. Y. Shi, Eledtroanal, 24, 2655 (2008) 